\title{
Blooming Date Predictions Based on Japanese Apricot 'Nanko' Flower Bud Responses to Temperatures during Dormancy
}

\author{
Yuto Kitamura \\ Japanese Apricot Laboratory, Wakayama Fruit Experimental Station, Minabe, \\ Hidaka, Wakayama 645-0021, Japan; and Graduate School of Agriculture, \\ Kyoto University, Sakyo-ku, Kyoto 606-8502, Japan \\ Hisayo Yamane ${ }^{2}$ \\ Graduate School of Agriculture, Kyoto University, Sakyo-ku, Kyoto 606- \\ 8502, Japan
}

\author{
Akira Yukimori ${ }^{1}$ and Hiroyoshi Shimo \\ Japanese Apricot Laboratory, Wakayama Fruit Experimental Station, \\ Minabe, Hidaka, Wakayama 645-0021, Japan
}

\section{Koji Numaguchi}

Japanese Apricot Laboratory, Wakayama Fruit Experimental Station, Minabe, Hidaka, Wakayama 645-0021, Japan; and Graduate School of Agricultural Science, Kobe University, Nada-ku, Kobe 657-8501, Japan

\section{Ryutaro Tao \\ Graduate School of Agriculture, Kyoto University, Sakyo-ku, Kyoto 606- 8502, Japan}

Additional index words. endodormancy, ecodormancy, development index, chilling requirement, heat requirement, Prunus mume

\begin{abstract}
Flower bud development and the timing of blooming are mainly affected by genotype-dependent chilling requirements (CRs) during endodormancy and subsequent heat requirements (HRs) during ecodormancy. However, little information is available regarding the responses of flower buds to temperatures during endodormancy and ecodormancy in japanese apricot. We exposed japanese apricot 'Nanko' trees to various temperatures to estimate the CRs and HRs using development index (DVI) models specific for the endodormant $\left(D V I_{\text {endo }}\right)$ and ecodormant (DVI $\left.I_{\text {eco }}\right)$ stages. These models were based on the experimentally determined development rate (DVR). The $D V R_{\text {endo }}$ value was calculated as the reciprocal of the chilling time required to break endodormancy. The relationship between the $D V R_{\text {endo }}$ value and temperature was estimated using a three-dimensional curve. Our results indicated that 5-6 ${ }^{\circ} \mathrm{C}$ was the most effective temperature for breaking endodormancy in 'Nanko' flower buds. Additionally, exposure to $-3{ }^{\circ} \mathrm{C}$ negatively affected endodormancy release, whereas $15{ }^{\circ} \mathrm{C}$ had no effect. We also determined that the $D V R_{\text {eco }}$ values for temperatures between 5 and $20^{\circ} \mathrm{C}$ were the reciprocal values of the time required for blooming after endodormancy release. The values outside this range were estimated using linear functions. The DVI was defined as the sum of the DVR values ranging from 0 to 1. Models for predicting the blooming date were constructed using the functions of sequentially combined DVI $I_{\text {endo }}$ and $D V I_{\text {eco }}$ models. The accuracy of each model was assessed by comparing the predicted and actual blooming dates. The prediction of the model in which DVI $I_{\text {eco }}=1$ corresponded to a $40 \%$ blooming level and $D V I_{\text {eco }}=0$ was set to $D V I_{\text {endo }}=0.5$ had the lowest root mean square error (RMSE) value (i.e., 3.11) for trees in commercial orchards exposed to different climates. Our results suggest that the developed model may have practical applications.
\end{abstract}

Japanese apricot (Prunus mume Sieb. et Zucc.) is one of the most popular fruit tree species in Japan for producing processed fruits and ornamental flowers (Mega et al., 1988). Most of the japanese apricot produced in Japan comes from Wakayama Prefecture, where the most popular cultivar, Nanko, usually blooms in the middle of February. However, the timing of the blooming stage varies depending on the year, with differences of up to 1 month. This fluctuation is an important factor affecting the synchronization of flowering between the major and pollinizer cultivars and the development of early spring frost damage, which can ultimately lead to unstable fruit production.

Flower buds of temperate deciduous fruit tree species enter endodormancy (i.e., suspension of visible growth due to internal factors) in the fall (Faust et al., 1997; Lang, 1987). After endodormant buds are exposed to a certain period of low temperatures, the buds are transferred to the ecodormant state and acquire the ability to resume growth under favorable conditions. Plant responses to low and high temperatures during endo- and ecodormancy, respectively, are critical factors for determining genotype-dependent blooming time. Additionally, recent global climate changes have also affected the timing of the blooming stage in trees, which may soon affect the suitability of certain areas for fruit tree cultivation (Sugiura et al., 2012). Thus, characterizing the specific temperature responses in each cultivar and estimating the timing of blooming are needed to achieve stable crop production. Japanese apricot trees ordinarily bloom at relatively low temperatures (Japanese Apricot Laboratory, personal communication), and most cultivars are self-incompatible (Miyake et al., 1995). Therefore, japanese apricot production is closely associated with climate conditions, and accurately predicting the blooming time is especially important.

In previous studies, the number of days transformed to standard temperature (DTS) was used to predict blooming times in several tree species, including Prunus yedoensis 'Somei-yoshino' and satsuma mandarin (Citrus unshiu Marcow.) (Hayashida et al., 1998; Omoto and Aono, 1989). In this DTS model, the degree of development is calculated using an Arrhenius equation, and blooming time is predicted by determining the most appropriate values for three parameters (i.e., initiation date, days required for blooming transformed to standard temperature, and temperature sensitivity) based on past measurements. The DTS model is highly accurate, but the predicted values may differ from the actual values depending on location and year (Ono and Konno, 1999). Moreover, flower buds of temperate deciduous trees undergo endodormancy and ecodormancy, and the responses of buds to temperature vary between the two phases. Incorporating these differences into the DTS model may increase its accuracy. The importance of considering the endodormancy release date for the DTS model has been discussed (Aono and Moriya, 2003; Aono and Sato, 1996; Ogata et al., 2006).

There have been several attempts to determine the chilling requirements for endodormancy release, and the following three models have been proposed: chill hour $(\mathrm{CH}$; Weinberger, 1950), chill unit (CU; Richardson et al., 1974), and chill portion (CP; Fishman et al., 1987a, 1987b). In the $\mathrm{CH}$ model, the number of hours plants are exposed to temperatures below $7.2^{\circ} \mathrm{C}\left(45^{\circ} \mathrm{F}\right)$ is counted. The $\mathrm{CU}$ model involves counting various weighted temperature values, with high temperatures negating the effects of 
previous exposures to low temperatures. The $\mathrm{CP}$ value is calculated using a dynamic model that assumes the chilling effects accumulate in a two-step process. Initially, exposure to low temperatures leads to the formation of a reversible intermediate product. If plants are then exposed to high temperatures, the product cannot be accumulated, whereas a subsequent exposure to low temperatures results in the production of an irreversible $\mathrm{CP}$ product. Gao et al. (2012) reported that of the three models, the CP model can most accurately predict the endodormancy release date in Nanjing, which is located in a relatively warm area in China. However, it is unclear whether the CP model is applicable for Japan.

A DVI model has been widely used to evaluate the progression of endodormancy release and blooming (Sugiura and Honjo, 1997; reviewed by Yamane, 2014). In this model, the DVR at each temperature is first calculated based on the experimentally determined time required for endodormancy release or blooming at constant temperature. For example, if trees need to be exposed to $7{ }^{\circ} \mathrm{C}$ for $500 \mathrm{~h}$ or $10{ }^{\circ} \mathrm{C}$ for $800 \mathrm{~h}$ to be released from endodormancy, the $\mathrm{DVR}_{\text {endo }}$ values at 7 and $10^{\circ} \mathrm{C}$ are $1 / 500$ and $1 / 800$ per hour, respectively. The growth stage is estimated for each time point based on the theoretical growth extent per unit time at a given temperature, and is recorded as the accumulated DVR value (i.e., DVI). For example, the $\mathrm{DVI}_{\text {endo }}$ value is 1.0 when trees accumulate the theoretically required amount of chilling for endodormancy release. The DVI model can be used to quantify almost all development-related phenomena affected by temperature sensitivity. This model has been used to estimate the panicle initiation and heading date in rice (Oryza sativa L.) (Nakagawa and Horie, 1995) and the endodormancy release date in japanese pear (Pyrus pyrifolia Nakai) (Sugiura and Honjo, 1997), peach [Prunus persica (L.) Batsch] (Pawasut et al., 2004; Sugiura et al., 2010), and japanese chestnut (Castanea crenata Sieb. et Zucc.) (Sakamoto et al., 2015). It has also been used to predict the timing of bud burst in japanese persimmon (Diospyros kaki Thunb.) (Sugimura et al., 2006).

\footnotetext{
Received for publication 12 Sept. 2016. Accepted for publication 15 Dec. 2016.

We gratefully acknowledge Dr. Toshihiko Sugiura for providing valuable comments regarding the DVI model and reviewing the manuscript. We also thank Minehiro Nishino and Kei Nakanishi for managing the plant materials, and Hisashi Ide, Satoshi Inoue, and Atsuo Okada for helping to collect temperature and blooming date data at their private orchards. This study was supported by the Japan Society for the Promotion of Science (grant number 26252005 to $\mathrm{HY}$ ).

${ }^{1}$ Current address: Agriculture, Forestry and Fishery Promotions Department, Hidaka Promotions Bureau, Wakayama, 651 Takara, Yukawa-cho, Gobo, Wakayama 644-0011, Japan

${ }^{2}$ Corresponding author. E-mail: hyamane@kais. kyoto-u.ac.jp.
}

In this study, we evaluated the responses of japanese apricot 'Nanko' flower buds to different temperature treatments during endodormancy and ecodormancy, and calculated the DVR values for each temperature. We then used two different DVR values (i.e., $\mathrm{DVR}_{\text {endo }}$ and $\mathrm{DVR}_{\mathrm{eco}}$ ) to predict the blooming date of 'Nanko' flower buds. The accuracy of our predicted blooming dates was verified by comparing them with the actual blooming dates in commercial orchards.

\section{Materials and Methods}

Evaluation of responses to chilling temperatures during endodormancy. We conducted three experiments. First, we exposed potted japanese apricot trees to various temperatures to quantify the chilling requirement $(\mathrm{CR})$ for endodormancy release according to the DVI model. Second, we determined the HR for blooming after endodormancy release based on temperature treatments similar to those used in the first experiment. Finally, we developed a model to predict the blooming date by combining the DVI models for CRs and HRs. We assessed the accuracy of the model by comparing the predicted and actual blooming dates for trees in a commercial orchard.

Three-year-old japanese apricot 'Nanko' trees grown in $25-\mathrm{L}$ pots at the Japanese Apricot Laboratory were analyzed from 2013 to 2015 . Trees pruned to maintain one upright trunk with 1-year-old branches were kept at temperatures above $15{ }^{\circ} \mathrm{C}$ in a greenhouse until early November of each year to ensure plants were not exposed to low temperatures. Trees were artificially defoliated and individual trees were exposed to the following conditions in darkened phytotrons (i.e., 24 trees were used): $2{ }^{\circ} \mathrm{C}$ for $336,408,480,552$, or $624 \mathrm{~h} ; 5^{\circ} \mathrm{C}$ for $336,480,552,624$, or 696 $\mathrm{h} ; 7^{\circ} \mathrm{C}$ for 336,408 , or $480 \mathrm{~h} ; 10^{\circ} \mathrm{C}$ for 336 , $408,480,552$, or $696 \mathrm{~h} ; 12^{\circ} \mathrm{C}$ for 480,552 , 624 , or $768 \mathrm{~h}$; or $15^{\circ} \mathrm{C}$ for 480 or $720 \mathrm{~h}$. To evaluate the effects of freezing conditions, an additional three trees grown at $5{ }^{\circ} \mathrm{C}$ were incubated two to four times in a freezer set at $-3{ }^{\circ} \mathrm{C}$ for $24 \mathrm{~h}$, with certain intervals between treatments (Fig. 1). The trees exposed to chilling temperatures were transferred to a greenhouse and incubated at temperatures above $15^{\circ} \mathrm{C}$. The blooming percentages were recorded for $\approx 2$ months. The relationship between blooming percentage and chilling exposure time for each treated tree was estimated using the following logistic regression curve with threshold and inflection points set to $100 \%$ and $50 \%$ (i.e., blooming percentage), respectively:

$$
f\left(d_{c}\right)=100 /\left\{1+\exp \left[-\alpha_{1}\left(d_{c}-\alpha_{2}\right)\right]\right\}
$$

where $d_{c}, f\left(d_{c}\right), \alpha_{1}$, and $\alpha_{2}$ correspond to the chilling treatment time, predicted blooming percentage, relative blooming rate, and chilling treatment time at the inflection point (i.e. chilling treatment time required for endodormancy release in $50 \%$ of flower buds), respectively. The parameters $\alpha_{1}$ and $\alpha_{2}$ were determined using a least squares method. Using this equation, the chilling exposure time required to reach an $80 \%$ blooming

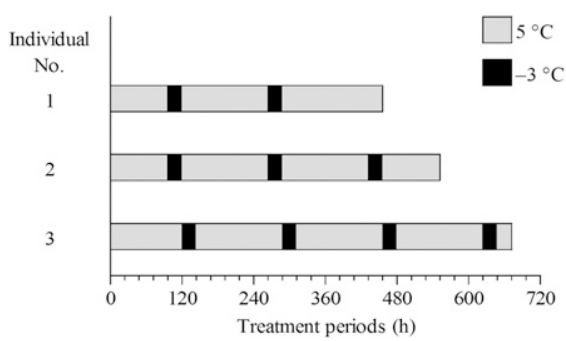

Fig. 1. Schedule of exposures to $-3{ }^{\circ} \mathrm{C}$ during incubations at $5{ }^{\circ} \mathrm{C}$. Total number of hours exposed to -3 and $5{ }^{\circ} \mathrm{C}$ were 48 and $408 \mathrm{~h}$ for sample 1, 72 and $480 \mathrm{~h}$ for sample 2, and 96 and $576 \mathrm{~h}$ for sample 3 , respectively.

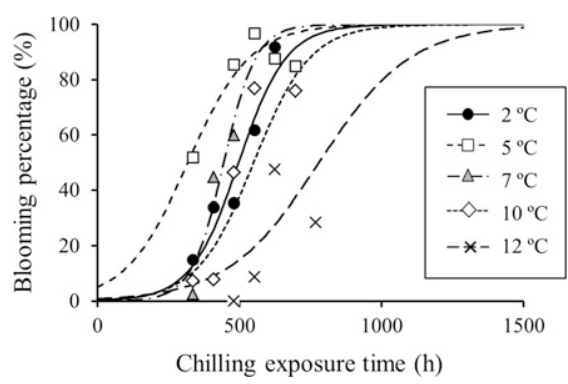

Fig. 2. Relationship between chilling exposure time and blooming percentage in japanese apricot 'Nanko' trees. The relationships were estimated using logistic regression curves. For $2{ }^{\circ} \mathrm{C}, f\left(d_{c}\right)=100 /\left\{1+\exp \left[-0.012\left(d_{c}-496.8\right)\right]\right\}$, $r^{2}=0.922$; for $5^{\circ} \mathrm{C}, f\left(d_{c}\right)=100 /\{1+\exp [-0.009$ $\left.\left.\left(d_{c}-317.9\right)\right]\right\}, r^{2}=0.810 ;$ for $7^{\circ} \mathrm{C}, f\left(d_{c}\right)=100 /$ $\left\{1+\exp \left[-0.018\left(d_{c}-444.6\right)\right]\right\}, r^{2}=0.865$; for $10{ }^{\circ} \mathrm{C}, f\left(d_{c}\right)=100 /\left\{1+\exp \left[-0.010\left(d_{c}-\right.\right.\right.$ 549.6)] $\}, r^{2}=0.903$; and for $12{ }^{\circ} \mathrm{C}, f\left(d_{c}\right)=$ $100 /\left\{1+\exp \left[-0.006\left(d_{c}-779.7\right)\right]\right\}, r^{2}=0.372$.

Table 1. Evaluation of $\mathrm{DVR}_{\text {endo }}$ values at $-3{ }^{\circ} \mathrm{C}$

\begin{tabular}{|c|c|c|c|c|c|c|}
\hline \multicolumn{2}{|c|}{ Time (h) } & \multirow{2}{*}{$\begin{array}{l}\text { Blooming } \\
\text { percentage }\end{array}$} & \multirow{2}{*}{$\begin{array}{c}\text { DVI at only } \\
5^{\circ} \mathrm{C}^{\mathrm{z}}\end{array}$} & \multirow{2}{*}{$\begin{array}{c}\text { Back calculated } \\
\text { DVI }^{\mathrm{y}}\end{array}$} & \multirow{2}{*}{$\begin{array}{c}\text { Value of } \\
\text { decreased DVI }\end{array}$} & \multirow{2}{*}{$\begin{array}{c}\text { DVR at } \\
-3{ }^{\circ} \mathrm{C}\left(\mathrm{h}^{-1}\right)\end{array}$} \\
\hline$-3^{\circ} \mathrm{C}$ & $5^{\circ} \mathrm{C}$ & & & & & \\
\hline 48 & 408 & 53.4 & 0.8703 & 0.7098 & 0.1605 & -0.0033 \\
\hline 72 & 480 & 66.3 & 1.0239 & 0.8354 & 0.1884 & -0.0026 \\
\hline 96 & 576 & 77.8 & 1.2287 & 0.9690 & 0.2597 & -0.0027 \\
\hline & & & & & Mean $\pm \mathrm{SE}$ & $-0.0029 \pm 0.00023$ \\
\hline
\end{tabular}

$\mathrm{DVR}_{\text {endo }}=$ endodormant development rate; DVI $=$ development index

${ }^{\mathrm{z}}$ Sum of the $\mathrm{DVR}_{\text {endo }}$ values assuming samples were continuously exposed to $5{ }^{\circ} \mathrm{C}$ for the duration of the treatment period.

${ }^{y}$ Sum of the $\mathrm{DVR}_{\text {endo }}$ values back-calculated from blooming percentages using $\mathrm{DVR}_{\text {endo }}$ regression curves. 
level for each temperature was calculated and defined as the CR. The DVR endo value for each temperature was calculated as the reciprocal of the $C R$ value.

The $\mathrm{DVR}_{\text {endo }}$ value at $-3{ }^{\circ} \mathrm{C}$ was determined based on the decreased $\mathrm{DVR}_{\text {endo }}$ accumulated values $\left(\mathrm{DVI}_{\text {endo }}\right)$ resulting from the freezing treatment. First, the $\mathrm{DVI}_{\text {endo }}$ value was back-calculated from the recorded blooming percentage using the $\mathrm{DVR}_{\text {endo }}$ function at $5{ }^{\circ} \mathrm{C}$. We then compared the assumed DVI $\mathrm{endo}_{\text {. }}$ value and the $\mathrm{DVI}_{\text {endo }}$ value for trees continuously exposed to $5^{\circ} \mathrm{C}$ to calculate the decreased $\mathrm{DVI}_{\text {endo }}$ value caused by exposure to $-3{ }^{\circ} \mathrm{C}$. Finally, the $\mathrm{DVR}_{\text {endo }}$ value per unit time at $-3{ }^{\circ} \mathrm{C}$ was determined by dividing the

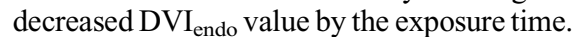
The $\mathrm{DVR}_{\text {endo }}$ value for each temperature was estimated according to the regression curve function.

Evaluation of responses to high temperatures during ecodormancy. We analyzed 3-year-old 'Nanko' trees grown as described above. After trees were exposed to $5{ }^{\circ} \mathrm{C}$ for $\approx 500 \mathrm{~h}$ in early November to break the endodormancy, they were incubated at 5 , 10,15 , or $20^{\circ} \mathrm{C}$ in phytotrons. We recorded the blooming percentages until all flower

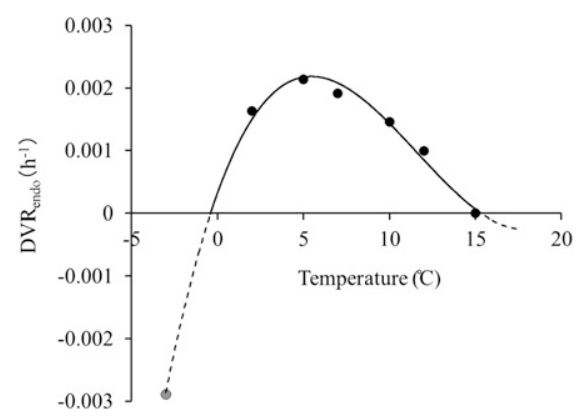

Fig. 3. Relationship between temperature and endodormant development rate $\left(\mathrm{DVR}_{\text {endo }}\right)$ value. The $\mathrm{DVR}_{\text {endo }}$ regression curve varies depending on how the endodormancy release date $\left(\mathrm{DVR}_{\text {endo }}=1\right.$ set point) is defined. For calculating the regression curve, the endodormancy release date was defined as the date when an $80 \%$ blooming level occurred. The relationship was estimated using a three-dimensional curve (i.e., dashed line): $\mathrm{DVR}_{\text {endo }}=$ $2.62 \mathrm{e}-06 t^{3}-9.12 \mathrm{e}-05 t^{2}+7.62 \mathrm{e}-04 t+$ $3.17 \mathrm{e}-04, r^{2}=0.996$, where $t$ refers to temperature. We used the values indicated by the solid line to develop a model for predicting the blooming date (refer to the text for more details). buds bloomed. We used three trees for each temperature treatment. The relationship between treatment time at each temperature and blooming percentage was estimated using the following logistic regression curve with threshold and inflection points set to $100 \%$ and $50 \%$ (i.e., blooming percentage), respectively:

$$
f\left(d_{h}\right)=100 /\left\{1+\exp \left[-\beta_{1}\left(d_{h}-\beta_{2}\right)\right]\right\}
$$

where $d_{h}, f\left(d_{h}\right), \beta_{1}$, and $\beta_{2}$ correspond to the time after endodormancy release, predicted blooming percentage, relative blooming rate, and time after endodormancy release at the inflection point (i.e., treatment time required for a $50 \%$ blooming rate), respectively. The parameters were determined as described above. The heating time required to reach a $30 \%, 40 \%$, or $50 \%$ blooming level at each temperature after endodormancy release was calculated and defined as the HR. The $\mathrm{DVR}_{\text {eco }}$ value for each temperature was calculated as the reciprocal of the HR value. The $\mathrm{DVR}_{\text {eco }}$ value at each temperature was estimated using the polygonal regression line function.

Construction and verification of a DVI model to predict the blooming date. During the 2013-14 and 2015-16 growing seasons, we selected one conventionally managed adult 'Nanko' tree planted at the Japanese Apricot Laboratory (Minabe, Hidaka, Wakayama, Japan; $33^{\circ} 49^{\prime} 4^{\prime \prime} \mathrm{N}, 135^{\circ} 21^{\prime} 8^{\prime \prime} \mathrm{E} ; 120 \mathrm{~m}$ above sea level). During the 2015-16 growing season, we also selected one tree each from three commercial orchards in Minabe to verify the accuracy of our model. The orchards were located in a coastal area $\left(33^{\circ} 47^{\prime} 2^{\prime \prime} \mathrm{N}, 135^{\circ} 20^{\prime} 1^{\prime \prime} \mathrm{E} ; 10 \mathrm{~m}\right.$ above sea level), mountainous area $\left(33^{\circ} 51^{\prime} 8^{\prime \prime} \mathrm{N}\right.$, $135^{\circ} 18^{\prime} 58^{\prime \prime} \mathrm{E}$; $160 \mathrm{~m}$ above sea level), and an area located between these two regions (i.e., middle area; $33^{\circ} 48^{\prime} 26^{\prime \prime} \mathrm{N}, 135^{\circ} 18^{\prime} 12^{\prime \prime} \mathrm{E} ; 150 \mathrm{~m}$ above sea level). We placed Ondotori Jr. TR-51 Thermo Recorders (T\&D Co., Matsumoto, Japan) in trees, and the temperature was recorded every hour from 1 Nov. until all flower buds bloomed. We recorded the blooming initiation date for each tree (i.e., the date when $\approx 20 \%$ of flower buds had bloomed).

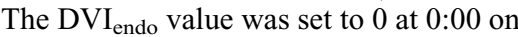
1 Nov. of each year. The DVI $I_{\text {endo }}$ value was calculated as the sum of the DVR endo $_{\text {values }}$ $\left(\Sigma \mathrm{DVR}_{\text {endo }}\right)$, and was set to 1 when the $\mathrm{CR}$ was satisfied. The $D_{V R}$ eco value started to increase when the $\mathrm{DVI}_{\text {endo }}$ value was $0.4,0.5$, 0.6 , or 0.7 . The $\mathrm{DVI}_{\text {eco }}$ value was calculated as the sum of the DVI $\mathrm{eco}_{\text {values }}\left(\Sigma \mathrm{DVR}_{\mathrm{eco}}\right)$,

Table 2. Coefficients of $D_{V R}$ endo regression curves when the endodormancy release date $\left(D_{V I} I_{\text {endo }}=1\right)$ was based on a $40 \%$ to $80 \%$ blooming level.

\begin{tabular}{lccccc}
\hline \multirow{2}{*}{$\begin{array}{l}\text { Definition of endodormancy } \\
\text { release }(\%)^{\mathrm{z}}\end{array}$} & $a$ & $b$ & $c$ & $d$ & $r^{2}$ \\
\cline { 2 - 5 } & $4.99 \mathrm{e}-06$ & $-1.61 \mathrm{e}-04$ & $1.29 \mathrm{e}-03$ & $1.77 \mathrm{e}-04$ & 0.986 \\
50 & $4.25 \mathrm{e}-06$ & $-1.37 \mathrm{e}-04$ & $1.08 \mathrm{e}-03$ & $3.61 \mathrm{e}-04$ & 0.992 \\
50 & $3.58 \mathrm{e}-06$ & $-1.18 \mathrm{e}-04$ & $9.32 \mathrm{e}-04$ & $4.31 \mathrm{e}-04$ & 0.995 \\
60 & $3.09 \mathrm{e}-06$ & $-1.03 \mathrm{e}-04$ & $8.20 \mathrm{e}-04$ & $4.56 \mathrm{e}-04$ & 0.997 \\
70 & $2.62 \mathrm{e}-06$ & $-9.12 \mathrm{e}-05$ & $7.62 \mathrm{e}-04$ & $3.17 \mathrm{e}-04$ & 0.996 \\
80 & &
\end{tabular}

$\mathrm{DVR}_{\text {endo }}=$ endodormant development rate; $\mathrm{DVI}_{\text {endo }}=$ endodormant development index.

${ }^{\mathrm{z}}$ Blooming percentage under forcing conditions.

${ }^{\mathrm{y}}$ Coefficients of the estimating function: $\mathrm{DVR}_{\text {endo }}=a t^{3}+b t^{2}+c t+d$, where $t$ refers to temperature. and was set to 1 when $30 \%, 40 \%$, or $50 \%$ of the flower buds had bloomed during the heat treatment. Our model consisted of a sequential combination of the $\mathrm{DVI}_{\text {endo }}$ and $\mathrm{DVI}_{\text {eco }}$ models. The predicted blooming dates for all models were compared with the actual blooming dates. We evaluated each model using the RMSE values.

\section{Results and Discussion}

Responses to low temperatures during endodormancy and development of the $D V I_{\text {endo }}$ model. The blooming levels for 3year-old japanese apricot 'Nanko' trees reached $91.9 \%, 85.4 \%, 60.0 \%$, and $76.9 \%$ following treatments at $2{ }^{\circ} \mathrm{C}$ for $624 \mathrm{~h}, 5{ }^{\circ} \mathrm{C}$ for $480 \mathrm{~h}, 7^{\circ} \mathrm{C}$ for $480 \mathrm{~h}$, and $10^{\circ} \mathrm{C}$ for $552 \mathrm{~h}$, respectively. Less than $50 \%$ of the flower buds in trees treated at $12{ }^{\circ} \mathrm{C}$ for $624 \mathrm{~h}$ bloomed, whereas no flower buds bloomed in trees incubated at $15{ }^{\circ} \mathrm{C}$. The relationship between treatment time and blooming percentage at each temperature was estimated using logistic regression curves (Fig. 2). We determined that incubations of $613.7,468.8$, $523.3,687.8$, and $1003.5 \mathrm{~h}$ were required for a blooming level of $80 \%$ at $2,5,7,10$, and $12{ }^{\circ} \mathrm{C}$, respectively. Therefore, the reciprocals of these times (i.e., $0.00163,0.00213$, $0.00191,0.00145$, and 0.001 ) corresponded

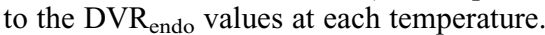

Blooming percentages were $53.4 \%$ for trees incubated at $5{ }^{\circ} \mathrm{C}$ for $408 \mathrm{~h}$ and $-3{ }^{\circ} \mathrm{C}$ for $48 \mathrm{~h}(24 \mathrm{~h} \times 2), 66.3 \%$ for trees incubated at $5{ }^{\circ} \mathrm{C}$ for $480 \mathrm{~h}$ and $-3{ }^{\circ} \mathrm{C}$ for $72 \mathrm{~h}(24 \mathrm{~h} \times 3)$, and $77.8 \%$ for trees incubated at $5{ }^{\circ} \mathrm{C}$ for $576 \mathrm{~h}$ and $-3{ }^{\circ} \mathrm{C}$ for $96 \mathrm{~h}(24 \mathrm{~h} \times 4)$. The $\mathrm{DVI}_{\text {endo }}$ values were back-calculated from these percentages using the regression curve at $5{ }^{\circ} \mathrm{C}$. The sum of the $\mathrm{DVR}_{\text {endo }}$ values for trees continuously incubated at $5{ }^{\circ} \mathrm{C}$ was subtracted from the back-calculated $\mathrm{DVI}_{\text {endo }}$ values to calculate the decreased DVI values resulting from the exposure to freezing conditions $\left(-3{ }^{\circ} \mathrm{C}\right)$ (Table 1). The decreased DVI values divided by exposure time at $-3{ }^{\circ} \mathrm{C}$ for three different treatments had relatively small SES. Therefore, the mean value (i.e., -0.0029) was used to represent the $\mathrm{DVR}_{\text {endo }}$ value at $-3{ }^{\circ} \mathrm{C}$. Because no flower buds bloomed in trees incubated at $15^{\circ} \mathrm{C}$, the $\mathrm{DVR}_{\text {endo }}$ value was considered to be 0 at $15{ }^{\circ} \mathrm{C}$.

The $\mathrm{DVR}_{\text {endo }}$ value at each temperature was estimated using a three-dimensional curve (Fig. 3, dashed line). However, the curve was calculated assuming that endodormancy was broken when $80 \%$ of the flower buds had bloomed. Because regression curve coefficients can vary depending on how endodormancy release is defined (i.e., what blooming level is

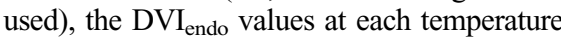
were affected by the blooming level used to determine the endodormancy release date (Table 2).

In the $\mathrm{CU}$ model for peach, the maximum $\mathrm{CU}$ value (i.e., 1) occurred at $2.4-9.1{ }^{\circ} \mathrm{C}$ (Richardson et al., 1974). The highest DVR values for endodormant flower buds of peach, japanese pear, and japanese chestnut were observed at $6{ }^{\circ} \mathrm{C}$ (Sakamoto et al., 2015; 


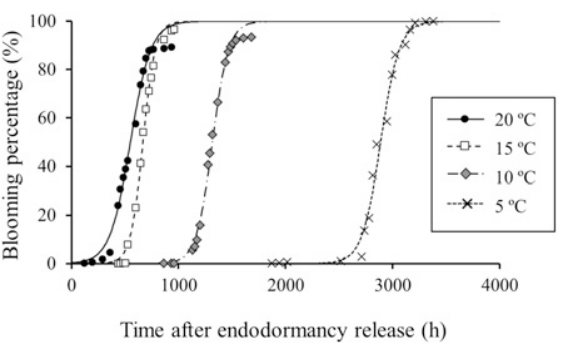

Fig. 4. Relationship between heat treatment time and blooming percentage at each temperature. The relationships were estimated using logistic regression curves. For $20^{\circ} \mathrm{C}, f\left(d_{h}\right)=100 /\{1+$ $\left.\exp \left[-0.011\left(d_{h}-550.1\right)\right]\right\}, r^{2}=0.989$; for $15^{\circ} \mathrm{C}$, $f\left(d_{h}\right)=100 /\left\{1+\exp \left[-0.017\left(d_{h}-667.4\right)\right]\right\}, r^{2}=$ 0.997 ; for $10{ }^{\circ} \mathrm{C}, f\left(d_{h}\right)=100 /\{1+\exp [-0.013$ $\left.\left.\left(d_{h}-1316.2\right)\right]\right\}, r^{2}=0.998$; and for $5^{\circ} \mathrm{C}, f\left(d_{h}\right)=$ $100 /\left\{1+\exp \left[-0.012\left(d_{h}-2888.4\right)\right]\right\}, r^{2}=0.990$.

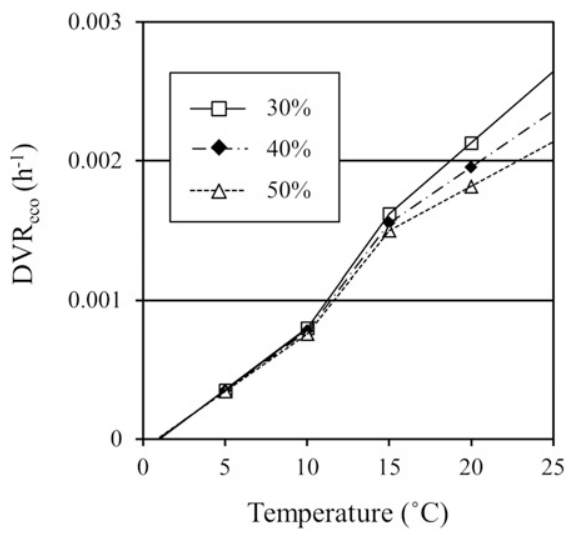

Fig. 5. Relationship between temperature and ecodormant development rate $\left(\mathrm{DVR}_{\mathrm{eco}}\right)$ value. The $\mathrm{DVR}_{\text {eco }}$ value varies depending on how the blooming date is defined. The blooming date was defined as the date when a $30 \%, 40 \%$, or $50 \%$ blooming level was observed during the heat treatment.
Sugiura et al., 2010; Sugiura and Honjo, 1997). The highest $D_{V R}$ endo value for japanese apricot occurred at $5-6{ }^{\circ} \mathrm{C}$, which likely corresponds to the most effective temperature for breaking endodormancy in temperate deciduous fruit tree species. However, the DVR value was determined to be 0 at temperatures above $12{ }^{\circ} \mathrm{C}$ in japanese pear (Sugiura and Honjo, 1997). We observed that temperatures greater than $15{ }^{\circ} \mathrm{C}$ produced a DVR value of 0 in japanese apricot, which was consistent with the results for peach (Sugiura et al., 2010). These observations suggest the effects of high temperatures on endodormancy release vary depending on species. Our data indicate that exposure to $-3{ }^{\circ} \mathrm{C}$ negatively affects endodormancy release in japanese apricot, which is in contrast with the findings for peach, which has a positive DVR value at $-3{ }^{\circ} \mathrm{C}$ (Sugiura et al., 2010). These results imply that japanese apricot trees have adapted to warmer climates and are more susceptible to the effects of cold stress than other fruit tree species. In other words, decreased blooming percentages are simply a consequence of $\mathrm{CI}$ due to exposure to $-3{ }^{\circ} \mathrm{C}$. The effects of temperatures below $-3{ }^{\circ} \mathrm{C}$ are unclear, but the accuracy of predictions based on our regression curve (Fig. 3; Table 2) would likely not be affected because of the infrequency of temperatures below $-3{ }^{\circ} \mathrm{C}$ in Wakayama Prefecture, even during winter in the open-field production sites. However, overestimating the negative effects of freezing temperatures on endodormancy release can affect the estimated endodormancy release date, especially in cold regions. Additionally, there are no reports suggesting that freezing temperature is associated with a negative DVR value in any other species. Therefore, when developing a model to predict the blooming date, we set negative $\mathrm{DVR}_{\text {endo }}$ values estimated by the regression curve to 0 (Fig. 3, solid line).

Responses to high temperatures during ecodormancy and development of the $D V I_{\text {eco }}$ model. Because exposure to $5{ }^{\circ} \mathrm{C}$ for $\approx 470 \mathrm{~h}$

Table 3. Differences between predicted and actual blooming initiation dates in analyzed fields. The predicted blooming dates vary depending on $\mathrm{DVI}_{\text {eco }}=0$ and $\mathrm{DVI}_{\text {eco }}=1$ set points. $\mathrm{The}^{\mathrm{DVI}} \mathrm{I}_{\text {endo }}=1$ set point is based on an $80 \%$ blooming level for endodormancy release.

\begin{tabular}{|c|c|c|c|c|c|c|c|c|}
\hline \multirow{5}{*}{$\begin{array}{l}\mathrm{DVI}_{\text {endo }} \text { as } \\
\text { initial point } \\
\text { of } \mathrm{DVI}_{\text {eco }}\end{array}$} & \multirow{5}{*}{$\begin{array}{c}\text { Definition of } \\
\text { blooming }(\%)^{z}\end{array}$} & \multicolumn{6}{|c|}{ Location and yr } & \multirow[b]{5}{*}{ RMSE } \\
\hline & & \multirow{2}{*}{\multicolumn{3}{|c|}{ Japanese Apricot Laboratory }} & \multicolumn{3}{|c|}{ Commercial orchards } & \\
\hline & & & & & \multirow{2}{*}{$\frac{\text { Coastal }}{2015-16}$} & \multirow{2}{*}{$\frac{\text { Middle }}{2015-16}$} & \multirow{2}{*}{$\frac{\text { Mountainous }}{2015-16}$} & \\
\hline & & $2013-14$ & $2014-15$ & $2015-16$ & & & & \\
\hline & & $2 / 4$ & $2 / 17$ & $2 / 4$ & $2 / 4$ & $2 / 11$ & $2 / 11$ & \\
\hline \multirow[t]{3}{*}{0.4} & 30 & -15 & -19 & -6 & -11 & -14 & 0 & 12.51 \\
\hline & 40 & -11 & -14 & -4 & -7 & -13 & +2 & 9.62 \\
\hline & 50 & -9 & -12 & -2 & -6 & -11 & +3 & 8.11 \\
\hline \multirow[t]{3}{*}{0.5} & 30 & -8 & 0 & -1 & -5 & -3 & +3 & 4.24 \\
\hline & 40 & -6 & +1 & +1 & -2 & 0 & +4 & 3.11 \\
\hline & 50 & -4 & +4 & +4 & 0 & +1 & +8 & 4.34 \\
\hline \multirow[t]{3}{*}{0.6} & 30 & -5 & +1 & +15 & +10 & +3 & +6 & 8.12 \\
\hline & 40 & -3 & +4 & +16 & +11 & +6 & +9 & 9.30 \\
\hline & 50 & -1 & +5 & +18 & +14 & +8 & +11 & 11.04 \\
\hline \multirow[t]{3}{*}{0.7} & 30 & -2 & +3 & +16 & +11 & +6 & +11 & 9.55 \\
\hline & 40 & 0 & +5 & +17 & +14 & +8 & +13 & 11.13 \\
\hline & 50 & +5 & +6 & +19 & +16 & +10 & +16 & 13.13 \\
\hline
\end{tabular}

$\mathrm{DVI}_{\text {eco }}=$ ecodormant development index; $\mathrm{DVI}_{\text {endo }}=$ endodormant development index; $\mathrm{RMSE}=$ root mean square error

${ }^{\mathrm{z}}$ Blooming percentage during heat treatment after $500 \mathrm{~h}$ of chilling. induced an $80 \%$ bloom and resulted in endodormancy release, we considered 'Nanko' trees incubated at $5{ }^{\circ} \mathrm{C}$ for $500 \mathrm{~h}$ to have shifted to the ecodormant stage. We observed that the higher the incubation temperature, the earlier the flower buds bloomed. The relationship between incubation time and blooming percentage at each temperature was estimated using logistic regression curves (Fig. 4). Based on the regression curves, incubations for $550.1,667.3,1316.2$, and $2888.4 \mathrm{~h}$ at 20,15 , 10 , and $5{ }^{\circ} \mathrm{C}$, respectively, were necessary to produce a $50 \%$ blooming level. Therefore, the reciprocals of these times (i.e., 0.00182 $0.00150,0.00076$, and 0.00035 ) represented the $\mathrm{DVR}_{\text {eco }}$ value at each temperature. The $\mathrm{DVR}_{\text {eco }}$ value varied depending on which blooming percentage corresponded to the blooming date (Fig. 5). The $\mathrm{DVR}_{\text {eco }}$ model consists of three linear functions associated with temperature ranges (i.e., $<10{ }^{\circ} \mathrm{C}, 10$ $15^{\circ} \mathrm{C}$, or $>15{ }^{\circ} \mathrm{C}$ ) (Fig. 5).

Previous studies on japanese pear adopted two linear regression functions using $20^{\circ} \mathrm{C}$ as a boundary to estimate the relationship between DVR values during ecodormancy and temperature (Oya, 2006; Sugiura et al., 1991). We were unable to obtain reliable blooming data for plants incubated at temperatures above $25{ }^{\circ} \mathrm{C}$ because many of the flower buds died (data not shown). Therefore, the function used for $15-20{ }^{\circ} \mathrm{C}$ was used for temperatures above $20{ }^{\circ} \mathrm{C}$. Ecodormant japanese apricot flower buds may be sensitive to high temperatures because flower buds continue to develop throughout winter, and flowers bloom while it is still cold. Further research is required to evaluate the effects of high temperatures on flowering. Additionally, when the regression function for $5-10^{\circ} \mathrm{C}$ was used for temperatures below $5^{\circ} \mathrm{C}$, the $\mathrm{DVR}_{\text {eco }}$ value was negative at $\approx 0{ }^{\circ} \mathrm{C}$. However, negative $\mathrm{DVR}_{\text {eco }}$ values at a given temperature are considered equivalent to 0 when the $\mathrm{DVI}_{\text {eco }}$ model is used to predict the blooming date.

Verification of the predicted blooming date. The flower buds of the 'Nanko' trees started to bloom at the Japanese Apricot Laboratory on 4 Feb. 2014, 17 Feb. 2015, and 4 Feb. 2016. The blooming initiation dates at commercial orchards in the coastal, moderately elevated, and mountainous areas in 2016 were 4 Feb., 11 Feb., and 11 Feb., respectively (Table 3).

Because the endodormancy of flower buds was gradually broken during exposures to low temperatures, the accumulation of heat during ecodormancy, which is necessary for blooming, likely begins before the endodormancy release date. Moreover, the functions of the $\mathrm{DVI}_{\text {endo }}$ and $\mathrm{DVI}_{\text {eco }}$ models vary depending on how the endodormancy release and blooming dates are defined. Therefore, the initial DVR $\mathrm{eco}_{\text {co }}$ value was set to $\mathrm{DVI}_{\text {endo }}=$ $0.4-0.7$, and the endodormancy release date $\left(\mathrm{DVI}_{\text {endo }}=1\right)$ and blooming date $\left(\mathrm{DVI}_{\mathrm{eco}}=1\right)$ were set to $40 \%$ to $80 \%$ and $40 \%$ to $60 \%$ blooming levels, respectively. Additionally, we verified the blooming date prediction for each model developed by sequentially combining the $\mathrm{DVI}_{\text {endo }}$ and $\mathrm{DVI}_{\text {eco }}$ models. 
The differences between the predicted and actual blooming dates for several orchards located in Wakayama are provided in Table 3 (except for clearly incorrect predictions). Preliminary validations of the models suggest that an $80 \%$ blooming level is the most suitable value for $\mathrm{DVI}_{\text {endo }}=1$ (data not shown). The RMSE values, which correspond to the accuracy of the models, were low when $\mathrm{DVI}_{\text {eco }}=1$ was set to a $40 \%$ blooming level and the initial $\mathrm{DVI}_{\text {eco }}$ value was set to $\mathrm{DVI}_{\text {endo }}=0.5$. With this combination, the differences between the predicted and actual blooming dates in 2014-15 and 2015-16 were up to $3 \mathrm{~d}$, whereas the difference in 2013-14 was 6 d. Unfortunately, the RMSE values in 2015-16 tended to be higher than those of the other years. Our model is based on data from a relatively small number of treatments because of the limited number of trees and availability of treatment space. Additionally, the treatments consisted of continuous exposures to low or high temperatures. A relatively mild winter in 2015-16 likely delayed endodormancy release, which may have resulted in increased error values.

The start of the blooming stage was accurately predicted for each analyzed year when the initial $\mathrm{DVI}_{\mathrm{eco}}$ value was set to $\mathrm{DVI}_{\text {endo }}=0.5$, likely because the temperature effects during the late stages of endodormancy were excluded from the model (Table 3). Oya (2006) developed a model to predict the blooming date of japanese pear by considerably adjusting the initial $\mathrm{DVI}_{\text {eco }}$ value after trees transitioned to the ecodormancy stage. This was done to minimize inaccurate predictions. The most suitable initial $\mathrm{DVI}_{\text {eco }}$ value was determined to be $\mathrm{DVI}_{\text {endo }}=2.2$. The differences between the models for japanese apricot and japanese pear suggest that the japanese apricot blooming date is affected more by the HR during ecodormancy than the CR of endodormancy, whereas both HR and CR have crucial effects on the blooming date of japanese pear.

For blooming date predictions, the DTS model requires data from several previous years, but data from new experiments are unnecessary. The $\mathrm{CH}, \mathrm{CU}$, and $\mathrm{CP}$ models were originally modified to be applicable for peach. Therefore, it is unclear whether these models can be used to analyze japanese apricot under changing climate conditions (e.g., global warming). Alternatively, although the DVI model requires the completion of complex experiments using many plants, DVI values can be used to represent developmental stages based on plant physiological reactions regardless of climate conditions. Our DVI model was verified in japanese apricot production sites in
Wakayama, Japan. The predicted and actual blooming dates differed by only a few days, indicating the developed model may have practical value. However, we generated limited experimental data for the temperatures during endodormancy $\left(-3{ }^{\circ} \mathrm{C}\right.$ to $\left.15^{\circ} \mathrm{C}\right)$ and ecodormancy $\left(5^{\circ} \mathrm{C}\right.$ to $\left.20^{\circ} \mathrm{C}\right)$. It is possible that the negative effects of temperatures below $-3{ }^{\circ} \mathrm{C}$ on endodormancy observed in this study are overestimated. To apply this model for other production sites or for climates affected by global warming, analyses involving a wider temperature range will be necessary.

\section{Literature Cited}

Aono, Y. and C. Moriya. 2003. A generalized model to estimate flowering for cherry tree (Prunus yedoensis) considering both processes of endodormancy completion and development. J. Agr. Meteorol. 59:165-177. (In Japanese with English abstract).

Aono, Y. and K. Sato. 1996. Estimation of flowering date for Japanese apricot tree (Prunus mume) in western Japan considering both processes of rest break and development. J. Agr. Meteorol. 52:125-134. (In Japanese with English abstract).

Faust, M., A. Erez, L.J. Rowland, S.Y. Wang, and H.A. Norman. 1997. Bud dormancy in perennial fruit trees: Physiological basis for dormancy induction, maintenance, and release. HortScience 32:623-629.

Fishman, S., A. Erez, and G.A. Couvillon. 1987a The temperature dependence of dormancy breaking in plants: Mathematical analysis of a two-step model involving a cooperative transition. J. Theor. Biol. 124:473-483.

Fishman, S., A. Erez, and G.A. Couvillon. 1987b. The temperature dependence of dormancy breaking in plants: Computer simulation of processes studied under controlled temperature. J. Theor. Biol. 126:309-321.

Gao, Z., W. Zhuang, L. Wang, J. Shao, X. Luo, B. Cai, and Z. Zhang. 2012. Evaluation of chilling and heat requirements in Japanese apricot with three models. HortScience 47:1826-1831.

Hayashida, S., I. Kishino, and A. Morita. 1998. Development of growth forecasting system on Satsuma mandarin. Bull. Nagasaki Fruit Tree Exp. Stn. 5:1-9. (In Japanese).

Lang, G.A. 1987. Dormancy-a new universal terminology. HortScience 22:817-820.

Mega, K., E. Tomita, S. Kitamura, S. Saito, and S. Mizukami. 1988. Ume, p. 289-300 (in Japanese). In: T. Aoba et al. (eds.). The grand dictionary of horticulture. Shogakukan, Tokyo, Japan.

Miyake, M., M. Yamaguchi, and T. Haji. 1995. The self-compatibility in mume cultivars (in Japanese). J. Jpn. Soc. Hort. Sci. 64(Suppl. 2):116-117.

Nakagawa, H. and T. Horie. 1995. Modeling and prediction of developmental process in rice. II. A model for simulating panicle development based on daily photoperiod and temperature. Jpn. J. Crop. Sci. 64:33-42. (In Japanese with English abstract).
Ogata, T., T. Takahara, N. Muramatsu, and H. Fujisawa. 2006. Experimental evaluation of temperature dependence of flower bud development in Satsuma mandarin. Bull. Natl. Inst. Fruit Tree Sci. 5:71-78. (In Japanese with English summary).

Omoto, Y. and Y. Aono. 1989. Estimation of blooming date for Prunus yedoensis by means of kinetic method. J. Agr. Meteorol. 45:25-31. (In Japanese with English abstract).

Ono, S. and T. Konno. 1999. Estimation of flowering date and temperature characteristics of fruit trees by DTS method. Jpn. Agr. Res. Q. 33:105-108.

Oya, Y. 2006. Prediction method for anthesis of Japanese pears based on weather habit reactions. Bull. Tochigi Agr. Exp. Stn. 58:7-16. (In Japanese with English summary).

Pawasut, A., N. Fujishige, K. Yamane, Y. Yamaki, and H. Honjo. 2004. Relationships between chilling and heat requirement for flowering in ornamental peaches. J. Jpn. Soc. Hort. Sci. 73:519-523.

Richardson, E.A., S.D. Seely, and D.R. Walker. 1974. A model for estimating the completion of rest for 'Redhaven' and 'Elberta' peach trees. HortScience 9:331-332.

Sakamoto, D., H. Inoue, S. Kusaba, T. Moriguchi, and T. Sugiura. 2015. The relationship between temperature and endodormancy completion in Japanese chestnut 'Porotan' (Castanea crenata Sieb. et Zucc.): Towards establishing a development rate (DVR). J. Agr. Meteorol. 71:106-110.

Sugimura, T., T. Urasaki, J. Imagawa, and M. Wakisaka. 2006. Estimation of endodormancy completion stage and bud burst stage in forced culture of Japanese persimmon (Diospyros kaki Thunb.) 'Tonewase' by developmental rate model. Hort. Res. (Japan) 5:45-49. (In Japanese with English summary).

Sugiura, T. and H. Honjo. 1997. The effects of temperature on endodormancy completion in Japanese pear (Pyrus pyrifolia Nakai) and modeling the relationship. J. Agr. Meteorol. 53:285-290. (In Japanese with English abstract).

Sugiura, T., S. Ono, F. Kamota, T. Asakura, T. Okuno, and S. Asano. 1991. A model for development rate from rest break to flowering of Japanese pear. J. Agr. Meteorol. 46:197203. (In Japanese with English summary).

Sugiura, T., D. Sakamoto, T. Asakura, and H. Sugiura. 2010. The relationship between temperature and effect on endodormancy completion in the flower bud of 'Hakuho' peach. J. Agr. Meteorol. 66:173-179. (In Japanese with English abstract).

Sugiura, T., H. Sumida, S. Yokoyama, and H. Ono. 2012. Overview of recent effects of global warming on agricultural production in Japan. Jpn. Agr. Res. Q. 46:7-13.

Weinberger, J.H. 1950. Chilling requirements of peach varieties. Proc. Amer. Soc. Hort. Sci. 56:122-128.

Yamane, H. 2014. Regulation of bud dormancy and bud break in Japanese apricot (Prunus mume Siebold \& Zucc.) and peach [Prunus persica (L.) Batsch]: A summary of recent studies. J. Jpn. Soc. Hort. Sci. 83:187-202. 